\title{
Routine abortion training matters for obstetrics and gynecology residents
}

\author{
Sahnah Lim ${ }^{1}$, Corey Westover ${ }^{2}$, Rini B. Ratan $^{2}$, Maryam Guiahi $^{3}$ \\ ${ }^{1}$ John Hopkins School of Public Health, Baltimore, USA \\ ${ }^{2}$ Department of Obstetrics and Gynecology, Columbia University, New York, USA \\ ${ }^{3}$ Department of Obstetrics and Gynecology, University of Colorado Anshutz, Aurora, USA \\ Email: slim28@jhu.edu
}

Received 13 November 2013; revised 2 December 2013; accepted 10 December 2013

Copyright (C) 2013 Sahnah Lim et al. This is an open access article distributed under the Creative Commons Attribution License, which permits unrestricted use, distribution, and reproduction in any medium, provided the original work is properly cited. In accordance of the Creative Commons Attribution License all Copyrights (C) 2013 are reserved for SCIRP and the owner of the intellectual property Sahnah Lim et al. All Copyright (C) 2013 are guarded by law and by SCIRP as a guardian

\begin{abstract}
Background: We set out to compare resident perspective regarding self-rated ability to perform abortion procedures, abortion attitudes and satisfaction with training at programs with routine and optional abortion training. Methods: We distributed surveys and conducted 1-h focus groups for 62 residents at six New York City OB/GYN programs; three offer routine abortion training. We compared resident survey responses at programs with routine versus optional training regarding self-rated ability to perform abortion procedures, abortion attitudes and satisfaction with training. We reviewed focus group transcripts to understand differences related to satisfaction with abortion training. Results: Residents at routine programs reported higher proportions of self-rated ability to perform abortion procedures (all surveyed procedures $p \leq 0.05$ ) and were more likely to fully participate in abortion services than residents at optional programs $(42 / 45$ vs. $12 / 17, p=0.03)$. Residents at routine programs were more likely to be "very satisfied" with training $(44 / 45$ vs. $12 / 17, p<0.001)$ based on three aspects of training: patient care management, self-rated ability to perform abortion procedures and rotation characteristics. Conclusion: Residents who received routine abortion training have higher rates of self-reported procedural competency and are more likely to be satisfied with training than residents who were offered optional training.
\end{abstract}

Keywords: Family Planning; Abortion Training; Obstetrics and Gynecology

\section{INTRODUCTION}

An integral part of obstetrics and gynecology (OB/GYN) training is abortion instruction [1,2]. As a result of political and religious controversies, however, many programs do not routinely train residents in abortion $[3,4]$. In an effort to improve $\mathrm{OB} / \mathrm{GYN}$ resident training, the Accreditation Council for Graduate Medical Education (ACGME) set forth a requirement in 1996 stating that "access to experience with induced abortion must be part of residency education"[5]. Since the 1996 ACGME requirement, there have been two other notable efforts to improve and formalize abortion training. Starting in 1999, the privately funded Ryan residency program has assisted $67 \mathrm{OB} / \mathrm{GYN}$ programs in the US, Puerto Rico, and Canada to integrate or formalize abortion training either in the hospital setting or by collaboration with a freestanding clinic (personal communication with Ryan program staff on 3/13/2013)[6]. In response to advocacy efforts of the National Abortion Reproductive Rights Action League (NARAL) chapter of New York, Mayor Michael Bloomberg introduced an abortion training initiative for OB/GYN residents at New York City (NYC) public hospitals in 2002 [7].

Despite these efforts, approximately half of US OB/ GYN program directors in 2004 reported that routine abortion training was not offered [3]. When routine abortion training occurs all residents are scheduled to participate in abortion services and may choose to opt out of certain aspects of the rotation based on personal objecttions. In contrast, when optional training is offered, residents must request or individually arrange participation in abortion services either on-site or at an outside institution or clinic. A national survey of recent 2007 OB/GYN graduates demonstrated that less than half of the respondents reported residency training in the full range of common first-trimester procedures; residents who trained at programs with optional training were less 
likely to be trained [8]. Discrepancies in training limit the number of new providers and contribute to the shortage of providers in many areas of the US [9].

We separately described the Bloomberg residency training initiative and enablers and barriers to abortion training within this context $[7,10]$. Of the six NYC training programs that we surveyed in our primary analysis, three continued to offer optional training. As an additional analysis, we compared residents' self-rated ability to perform abortion procedures, abortion attitudes and satisfaction with abortion training according to whether their training was routine or optional. To our knowledge, no previous studies have used a mixed-methodology approach to measure $\mathrm{OB} / \mathrm{GYN}$ resident attitudes about abortion provision and training at routine versus optional programs.

\section{METHODS}

The objective of this study was to determine whether residents at routine training programs have differing rates of self-reported procedural competency, different abortion attitudes and different rates of satisfaction with abortion training when compared to residents who were offered optional training. We used a mixed-methods approach; we distributed surveys and used focus group data to understand differences. The focus group data was part of a larger qualitative study [10]. By using a mixedmethod approach we were able to combine the strength of both qualitative and quantitative research methods: the ability to describe resident perspective in greater detail combined with statistical reliability and the opportunity for data triangulation [11].

We obtained Institutional Review Board approval from Columbia University Medical Center and from seven NYC public hospital facility research review committees. An eighth research review committee did not reply to our request and was therefore omitted from recruitment. One residency director replied but declined resident participation, leaving six programs eligible for participation.

We contacted the residency director or an attending physician at each eligible program to organize enrollment of their residents into this study. We collected program characteristics from these contacts and arranged 1-h meetings during residents' protected educational time. At each program, all available residents participated in a 30-60 min focus group led by the primary investigator (MG) and an assistant; no residents were excluded. Unavailable residents included those who were on night rotations or on vacation. If we received permission, we tape-recorded the interview. During our introduction, we obtained oral consent, and explained to the residents that any institution or employee name would be de-identified during transcription. We used detailed, semi-structured interview guides to discuss resident training experience.
After the interview, we distributed paper surveys. The surveys assessed personal characteristics and residency ranking considerations, their self-assessed ability to perform abortion procedures, abortion attitudes and assessed satisfaction with training. For ranking considerations we asked residents if they desired abortion training when applying and if abortion training was favorably/unfavorably considered when ranking. We asked residents to rate their ability according to whether they "can perform on own" "can perform with help" or "cannot perform" the following abortion procedures: medication abortion, suction curettage [manual vacuum aspiration (MVA), electric vacuum aspiration (EVA)] and dilation and evacuation (D\&E). For attitudes, we asked residents, "How important do you think it is that $\mathrm{OB} / \mathrm{GYN}$ residents receive abortion training?" using a 4-point scale (1 $=$ very unimportant, $2=$ somewhat unimportant, $3=$ somewhat important, $4=$ very important) and if they opted out of abortion services during residency. Regarding future practice intentions, we asked residents whether they "plan to" "may" or "will not" perform a list of procedures. Finally, we assessed satisfaction with train- ing by asking "How satisfied are you with the abortion training at your residency program?" and using a 4-point scale to respond ( 1 = very unsatisfied, $2=$ unsatisfied, 3 $=$ satisfied. $4=$ very satisfied).

We analyzed survey data using SPSS (version 18.0; SPSS Chicago, IL, USA). We compared residents at routine versus optional programs with respect to personal characteristics, self-assessed procedural competencies, attitudes and training satisfaction using Fisher's exact test and Pearson's chi-square. For all comparisons of self-assessed competencies based on type of training, postgraduate year was included in our regression models. For abortion attitudes and satisfaction with training we included desire for abortion training in our models.

Although this manuscript focused on data from the survey, we integrated relevant focus group data in order to elucidate the substantive reasons for resident satisfaction with training. The details of our qualitative approach have been described elsewhere [10]. In brief, we reviewed focus group transcripts and engaged in an iterative and comparative form of analysis, using grounded theory to allow themes to emerge as it related to differences found in our survey.

\section{RESULTS}

Six programs in NYC participated in our study; three provided routine training and three offered optional training. Sixty-two of the 150 residents $(44 \%)$ who train at these programs participated in our focus group and completed surveys. Participation rates in each program ranged from $25 \%$ to $58 \%$. The remaining residents were unavailable due to scheduling constraints. We tape-re- 
corded five of the six focus groups and took handwritten notes at one program that declined audio recording.

Program and resident characteristics are described in Tables 1 and 2, respectively. Programs with routine training were larger, had a Ryan program, and offered training for a full range of abortion procedures. Although most Ryan programs have formalized routine abortion training curriculums, one Ryan program surveyed in our study continued to offer optional on-site training. None of the three optional training programs provided medical abortion training. Most of the residents who participated in the study were female, less than 30 years old, married or with a long-term partner, and attended a religious activity less than once a month. Residents at programs with routine training were younger (28 versus 31 , mean age), more likely to be Caucasian or Asian, and less likely to attend monthly religious services. They were also more likely to have desired abortion training compared to residents at programs with optional training $(\mathrm{p}=0.01)$. Only one resident in our cohort reported that he/she ranked programs with abortion training lower; this resident matched into a program with routine training.

Table 3 compares differences in self-rated ability to perform abortion procedures based on whether residents received routine or optional training. When we controlled for level of training (i.e. post-graduate level 1, 2, 3, and 4), residents at programs with routine training were more likely to report that they can independently perform all of the listed abortion procedures (Table 3), as compared to residents at optional programs.

Resident abortion attitudes and satisfaction with abortion training are described in Table 4 . Over $90 \%$ of participating residents, regardless of type of training, rated abortion training as very important. Residents at programs with routine training, however, were less likely to opt out of abortion training and more likely to plan to perform various abortion procedures after residency completion. We examined the impact of desire for abortion training and found that desire for abortion training prior to residency was an important contributor to plans to perform EVA $(p=0.02)$ and D\&E $(p<0.001)$ after graduation; type of training did not remain significant in our adjusted model.

Residents at routine programs were also more likely to be satisfied with their abortion training, even after accounting for desire for abortion training $(p<0.001)$. Given this significant difference, we reviewed focus group transcripts from our larger mixed-methods study to understand. This review revealed that residents at programs with routine training reported satisfaction based on three aspects of their training experience: patient care management, procedural competency and rotation characteristics. First, residents at routine programs reported that exposure to a substantial number of patients desiring
Table 1. Characteristics at routine versus optional training programs.

\begin{tabular}{ccc}
\hline & $\begin{array}{c}\text { Routine } \\
\text { programs (n=3) }\end{array}$ & $\begin{array}{c}\text { Optional } \\
\text { programs (n=3) }\end{array}$ \\
\hline $\begin{array}{c}\text { Mean number of } \\
\text { residents/year (range) }\end{array}$ & $8(7-11)$ & $3(3-4)$ \\
Affiliation with medical school & $100 \%$ & $33 \%$ \\
$\begin{array}{c}\text { Secular medical school } \\
\text { Faith-based medical school }\end{array}$ & $100 \%$ & $0 \%$ \\
Collaboration with Ryan program & $0 \%$ & $100 \%$ \\
$\quad \begin{array}{c}\text { Abortion experience } \\
\text { Medical abortion training }\end{array}$ & $100 \%$ & $33 \%$ \\
Manual vacuum aspiration training & $100 \%$ & $0 \%$ \\
Electric vacuum aspiration & $100 \%$ & $33 \%$ \\
$\quad$ training & $100 \%$ & $100 \%$ \\
$\begin{array}{c}\text { Dilation and evacuation } \\
\text { for fetal/maternal indications } \\
\text { Dilation and evacuation } \\
\text { for any indication }\end{array}$ & $100 \%$ & $100 \%$ \\
\hline
\end{tabular}

*Varying gestational age limit.

abortion services improved their ability to provide care, ultimately leading to higher satisfaction with their training.

Second, residents at routine training programs explained that participating in the family planning rotation improved their procedural competency specifically related to first trimester ultrasound, outpatient procedures such as MVAs, and D\&E. Residents at programs with optional training, on the other hand, reported low exposure to all aspects of abortion care and some reported that this hindered their ability to appropriately provide options counseling when patients needed referrals. They also explained that lack of procedural training affected their ability to provide abortion care after graduation.

Third, residents at programs with routine training described several rotation characteristics that contributed to their high level of satisfaction. In these settings, only one resident was assigned to the rotation at a time. Residents enjoyed this because they directly reviewed patient care plans with the attending physician(s) and participated in all aspects of patient care management. At these programs, the residents who opted out appreciated how their modified rotations were tailored by the attending(s) to meet their learning goals. They also described that the curriculum was structured and included assigned readings, educational lectures and related journal clubs. Another rotation characteristic that residents cited was rotating within a dedicated women's options clinic where residents appreciated patient-centered care and reported receiving administrative and psychosocial support from the support staff.

\section{CONCLUSIONS}

The value of abortion training and its impact on future 
Table 2. Respondent characteristics at routine versus optional training programs.

\begin{tabular}{|c|c|c|c|}
\hline Respondent characteristics & $\begin{array}{c}\text { Routine } \\
\text { programs } \\
\mathrm{N}=45\end{array}$ & $\begin{array}{c}\text { Optional } \\
\text { programs } \\
\mathrm{N}=17\end{array}$ & $\mathrm{P}$ \\
\hline Gender & & & 0.33 \\
\hline Male & $3(6.7)$ & $3(17.6)$ & \\
\hline Female & $42(93.3)$ & $14(82.4)$ & \\
\hline Age, years & & & 0.01 \\
\hline$<30$ & $34(75.6)$ & $5(29.4)$ & \\
\hline$\geq 30$ & $11(24.4)$ & $12(70.6)$ & \\
\hline Postgraduate year level & & & 0.68 \\
\hline 1 & $17(37.8)$ & $4(23.5)$ & \\
\hline 2 & $9(20.0)$ & $5(29.4)$ & \\
\hline 3 & $9(20.0)$ & $3(17.6)$ & \\
\hline 4 & $10(22.2)$ & $5(29.4)$ & \\
\hline Race & & & 0.02 \\
\hline Caucasian & $26(57.8)$ & $2(11.8)$ & \\
\hline Hispanic & $5(11.1)$ & $3(17.6)$ & \\
\hline Black/African American & $6(13.3)$ & $4(23.5)$ & \\
\hline Asian & $8(17.8)$ & $8(47.1)$ & \\
\hline Religion & & & 0.08 \\
\hline Catholic & $19(42.2)$ & $5(29.4)$ & \\
\hline Other Christian denomination & $7(15.6)$ & $3(17.6)$ & \\
\hline Other religions & $11(24.4)$ & $9(52.9)$ & \\
\hline Unaffiliated & $8(17.8)$ & $0(0)$ & \\
\hline Frequency of religious activity & . & & 0.02 \\
\hline$\geq$ Once per month & $7(15.6)$ & $8(47.1)$ & \\
\hline$<$ Once a month & $38(84.4)$ & $9(52.9)$ & \\
\hline Marital status & & & 1.00 \\
\hline Never married/divorced & $17(37.8)$ & $7(41.2)$ & \\
\hline Married/long-term & $28(62.2)$ & $10(58.8)$ & \\
\hline $\begin{array}{l}\text { Desired abortion training at time } \\
\text { of residency application } \\
\text { Definitely/Probably Yes } \\
\text { Definitely/ Probably No }\end{array}$ & $\begin{array}{l}30(66.7) \\
15(33.3)\end{array}$ & $\begin{array}{c}5(29.4) \\
12(70.6)\end{array}$ & 0.01 \\
\hline $\begin{array}{l}\text { Programs with more abortion } \\
\text { training were ranked: }\end{array}$ & & & \\
\hline Higher (preferred training) & $32(71.1)$ & $5(29.4)$ & $<0.01$ \\
\hline Lower (did not prefer training) & $1(2.2)$ & $0(0)$ & \\
\hline Not applicable & $12(26.7)$ & $12(70.6)$ & \\
\hline
\end{tabular}

service provision has been highlighted by previous investigators using single and multi-site study descriptions at both $\mathrm{OB} / \mathrm{GYN}$ and family medicine training programs [12-15]. Our study is the first to compare OB/GYN resident experience and perspectives at both routine and optional abortion training programs using mixed-methodology.

In our study, we found that residents who desired abortion training were more likely to rank programs with routine training higher and subsequently match. This desire impacted their plans for provision of abortion ser-
Table 3. Self-reported ability to perform abortion procedures at routine versus optional training programs.

\begin{tabular}{|c|c|c|c|c|}
\hline $\begin{array}{l}\text { Self-reported ability to } \\
\text { perform abortion methods } \\
\text { (Can "perform on own") }\end{array}$ & $\begin{array}{l}\text { Routine } \\
\mathrm{N}=45\end{array}$ & $\begin{array}{l}\text { Optional } \\
\mathrm{N}=17\end{array}$ & $\begin{array}{c}\text { Unadjusted } \\
\text { P }\end{array}$ & $\begin{array}{l}\text { d Adjusted } \\
\qquad \mathrm{P}^{*}\end{array}$ \\
\hline Medication abortion & $24(53.5)$ & $4(23.5)$ & 0.05 & 0.03 \\
\hline Manual vacuum aspiration & $33(73.3)$ & $6(35.3)$ & $<0.01$ & $<0.01$ \\
\hline Electric vacuum aspiration & $36(80.0)$ & $10(58.8)$ & 0.11 & 0.05 \\
\hline Dilation and evacuation & $17(37.8)$ & $2(11.8)$ & 0.07 & 0.04 \\
\hline
\end{tabular}

Data shown for routine and optional programs are n (\%). P values are Fisher's exact test. ${ }^{*}$ Adjusted for level of training.

Table 4. Residents' abortion attitudes and satisfaction with abortion training at routine versus optional programs.

\begin{tabular}{ccccc}
\hline Abortion attitude & $\begin{array}{c}\text { Routine } \\
\mathrm{N}=45 \\
(73 \%)\end{array}$ & $\begin{array}{c}\text { Optional } \\
\mathrm{N}=17 \\
(27 \%)\end{array}$ & $\begin{array}{c}\text { Unadjusted } \\
\mathrm{P}\end{array}$ & $\begin{array}{c}\text { Pdjusted } \\
\mathrm{P}\end{array}$ \\
\hline $\begin{array}{c}\text { Abortion training is } \\
\text { very important } \\
\begin{array}{c}\text { Opted-out of } \\
\text { abortion training }\end{array}\end{array}$ & $33(95.6)$ & $14(82.4)$ & 0.12 & 0.28 \\
$\begin{array}{c}\text { Plans to perform manual } \\
\text { vacuum aspiration }\end{array}$ & $38(84.4)$ & $1(58.8)$ & 0.04 & 0.16 \\
$\begin{array}{c}\text { Plans to perform electric } \\
\text { vacuum aspiration }\end{array}$ & $38(84.4)$ & $10(58.8)$ & 0.04 & 0.23 \\
$\begin{array}{c}\text { Plans to perform dilation } \\
\text { and evacuation }\end{array}$ & $34(75.6)$ & $7(41.2)$ & 0.02 & 0.19 \\
$\begin{array}{c}\text { Plans to perform } \\
\text { medication abortion }\end{array}$ & $37(82.2)$ & $11(64.7)$ & 0.18 & 0.27 \\
$\begin{array}{c}\text { Very satisfied with } \\
\text { abortion training }\end{array}$ & $44(97.5)$ & $5(29.4)$ & $<0.001$ & $<0.001$ \\
\hline
\end{tabular}

Data for routine and optional programs are $\mathrm{n}(\%)$. P values are Fisher's exact test. Adjusted $\mathrm{P}$ values account for desire for abortion training when ranking. "Will perform" or "may perform" vs. "will not perform".

vices after graduation. Although a self-selection process seemed to exist, all of the residents in our study valued abortion training and none of the residents at optional programs reported that they did not want training. Consistent with Jackson's national survey [8], residents at routine programs in our study were more likely to be exposed to a comprehensive abortion curriculum. It appears that comprehensive training favorably impacts residents' procedural confidence level.

Our study documents increasing evidence of the importance of inclusion of routine structured abortion training with an opt-out provision at all programs. According to the ACGME, all OB/GYN residents are expected to have adequate training in induced abortion. Even if residents do not plan to perform abortions, they must be exposed to training in order to better understand and care for women who may seek information and services from them. Exposure to induced abortion training improves resident competency and likelihood to perform abortion care $[9,16,17]$ and other reproductive health 
care services, such as management of early pregnancy failures, after graduation [17]. Offering optional training is not only insufficient but also problematic; residents should not be held responsible for arranging off-site opportunities.

There are limitations to our study. We used convenience sampling to recruit residents, which led to incomeplete participation. Participation, however, was not based on interest in the study; focus groups took place during residents' protected academic time so all available residents participated including residents who opted out of abortion training. We also had small overall participation numbers which precluded us from measuring the effects of other potential confounders. Finally, although we did not survey the number of procedures performed by residents or use a validated measure to assess competency, Mandel et al. [18] have demonstrated that OB/GYN residents self-assess well compared to faculty observers.

Residents at routine programs in our study expressed more favorable views about their abortion training when a dedicated family planning rotation was offered, which has been previously described $[12,15]$. In our study, structured abortion training occurred with the assistance of the Ryan program. The Ryan program helps provide curricular support and assists with training opportunities either on-site or by collaboration with a freestanding clinic. We encourage program directors looking to implement or improve induced abortion training to collaborate with this program. By increasing the number of programs that provide routine instruction, we may potentially increase the number of abortion providers throughout the US. Such improvements may ultimately ensure that women throughout the country have access to well-trained, competent providers to meet their reproductive health care needs.

\section{REFERENCES}

[1] The Council on Resident Education in Obstetrics and Gynecology: Educational Objectives: Core Curriculum in Obstetrics and Gynecology, Ed., CREOG. 2009, Professional Publishing Group, Ltd., New York.

[2] (2009) ACOG Committee Opinion No. 424: Abortion access and training. Obstetrics \& Gynecology, 113, 247250 .

[3] Eastwood, K.L., Kacmar, J.E., Steinauer, J., Weitzen, S. and Boardman, L.A. (2006) Abortion training in United States obstetrics and gynecology residency programs. $\mathrm{Ob}$ stetrics \& Gynecology, 108, 303-308.

http://dx.doi.org/10.1097/01.AOG.0000224705.79818.c9

[4] Almeling, R., Tews, L.and Dudley, S. (2000) Abortion training in US obstetrics and gynecology residency programs, 1998. Family Planning Perspectives, 32, 268-271, 320. http://dx.doi.org/10.2307/2648194

[5] ACGME (2011) Obstetrics/Gynecology Program Requirements.
http://www.acgme.org/acgmeweb/Portals/0/PFAssets/Pro gramRsources/220_OBGYN_Abortion_Training_Clarific ation.pdf

[6] Ryan Program. (2011) The Kenneth J. Ryan Residency Training Program in Abortion and Family Planning. http://www.ryanprogram.org

[7] Guiahi, M., Westover, C., Lim, S. and Westhoff, C.L. (2012) The New York City mayoral abortion training initiative at public hospitals. Contraception, 86, 577-582. http://dx.doi.org/10.1016/j.contraception.2012.02.010

[8] Jackson, C.B. and Foster, A.M. (2012) Ob/Gyn training in abortion care: Results from a national survey. Contraception, 86, 407-412.

http://dx.doi.org/10.1016/j.contraception.2012.02.007

[9] Shanahan, M.A., Metheny, W.P., Star, J. and Peipert, J.F. (1999) Induced abortion. Physician training and practice patterns. The Journal of Reproductive Medicine, 44 428432.

[10] Guiahi, M., Westover, C., Lim, S. and Westhoff, C.L. (2011) Enablers and barriers to abortion training in New York City. Contraception, 84, 308-309.

http://dx.doi.org/10.1016/j.contraception.2011.05.027

[11] Creswell, J.W., Fetters, M.D. and Ivankova, N.V. (2004) Designing a mixed methods study in primary care. The Annals of Family Medicine, 2, 7-12. http://dx.doi.org/10.1370/afm.104

[12] Steinauer, J., Drey, E.A., Lewis, R., Landy, U. and Learman, L.A. (2005) Obstetrics and gynecology resident satisfaction with an integrated, comprehensive abortion rotation. Obstetrics \& Gynecology, 105, 1335-1340. http://dx.doi.org/10.1097/01.AOG.0000158859.35943.be

[13] Steinauer, J.E., Landy, U., Jackson, R.A. and Darney, P.D. (2003) The effect of training on the provision of elective abortion: A survey of five residency programs. American Journal of Obstetrics \& Gynecology, 188, 11611163. http://dx.doi.org/10.1067/mob.2003.309

[14] Paul, M., Nobel, K., Goodman, S., Lossy, P., Moschella, J.E. and Hammer, H. (2007) Abortion training in three family medicine programs: Resident and patient outcomes. Family Medicine Journal, 39, 184-189.

[15] MacIsaac, L. and Vickery, Z. (2012) Routine training is not enough: structured training in family planning and abortion improves residents' competency scores and intentions to provide abortion after graduation more than ad hoc training. Contraception, 85, 294-298. http://dx.doi.org/10.1016/j.contraception.2011.06.014

[16] Steinauer, J., Landy, U., Fillipone, H., Laube, D., Darney, P.D. and Jackson, R.A. (2008) Predictors of abortion provision among practicing obstetrician-gynecologists: A national survey. American Journal of Obstetrics \& Gynecology, 198, 39 E1-E6.

[17] Dalton, V.K., Harris, L.H., Bell, J.D., et al. (2011) Treatment of early pregnancy failure: Does induced abortion training affect later practices? American Journal of $\mathrm{Ob}$ stetrics \& Gynecology, 204, E1-E6.

[18] Mandel, L.S., Goff, B.A. and Lentz, G.M. (2005) Self-assessment of resident surgical skills: Is it feasible? American Journal of Obstetrics \& Gynecology, 193, 18171822 . 